\title{
PREVALENCE AND SEVERITY OF ANAEMIA AMONG HOSPITALISED CHILDREN AGED 6-59 MONTHS
}

\author{
Sajini Varghese ${ }^{1}$, Surya Kandashamparambil Kamalakarababu², Suresh Sebastian Vadakkedam ${ }^{3}$
}

${ }^{1}$ Assistant Professor, Department of Paediatrics, Government Medical College, Kottayam.

${ }^{2}$ Assistant Professor, Department of Paediatrics, Government Medical College, Kottayam.

${ }^{3}$ Assistant Professor, Department of Paediatrics, Government Medical College, Kottayam.

\section{ABSTRACT}

\section{BACKGROUND}

Anaemia is ubiquitous and has a global prevalence, more so in developing countries. Globally, anaemia affects 1.62 billion people, which corresponds to $24.8 \%$ of the population and the highest prevalence is noted in preschool-age children (47.4\%). Anaemia is a major health problem in India. Iron deficiency, the most common cause for anaemia can be effectively prevented and in case already developed, can be easily treated by simple measures. Hence, there is a dire necessity for comprehensive studies to determine the prevalence of anaemia in children.

\section{MATERIALS AND METHODS}

This is a retrospective descriptive study conducted at Institute of Child Health, Government Medical College, Kottayam. Data pertaining to gender, age, weight, serum haemoglobin level, diagnosis that led to admission and duration of hospitalisation were collected. The WHO criteria (haemoglobin $<11 \mathrm{~g} / \mathrm{dL}$ ) were used to diagnose anaemia. Chi-square test was used to find the association between grades of anaemia and various study parameters.

\section{RESULTS}

Prevalence of anaemia was $56.1 \%$ in the study group with $28.7 \%, 25.3 \%$ and $2.1 \%$ as mild, moderate and severe anaemia respectively. Proportion of anaemic cases decreased with age, varying from $71.3 \%$ in children between 6 and 12 months to $31.5 \%$ in children $>36$ months.

\section{CONCLUSION}

A large proportion of hospitalised children less than 5 years of age were found anaemic. Among all the anaemic children, iron deficiency anaemia was high and it should be considered as a public health problem.

\section{KEYWORDS}

Anaemia, Iron Deficiency Anaemia, Prevalence, Severity, Nutritional Status.

HOW TO CITE THIS ARTICLE: Varghese S, Kamalakarababu SK, Vadakkedam SS. Prevalence and severity of anaemia among hospitalised children aged 6-59 months. J. Evolution Med. Dent. Sci. 2017;6(82):5750-57504, DOI: 10.14260/jemds/2017/1247

\section{BACKGROUND}

Anaemia is ubiquitous and has a global prevalence, more so in developing countries. Globally, anaemia affects 1.62 billion people, which corresponds to $24.8 \%$ of the population and the highest prevalence is noted in preschool-age children $(47.4 \%){ }^{1}$ Anaemia is a major health problem in India. Seven out of every 10 children aged 6-59 months in India are anaemic and as per 2005-2006 National Family Health Survey (NFHS-3), the prevalence of anaemia was $70 \%$ in children aged 6-59 months with three percent severely anaemic, 40 percent moderately anaemic, and 26 percent mildly anaemic. ${ }^{2}$

In spite of being ubiquitous, mild and moderate anaemia is generally asymptomatic apart from malaise, irritability and anorexia which hardly convince the parents to bring their wards for a medical checkup. Hence, anaemia has to be actively sought out in this vulnerable population and $\mathrm{Hb}$

'Financial or Other Competing Interest': None.

Submission 29-08-2017, Peer Review 30-10-2017,

Acceptance 06-10-2017, Published 12-10-2017.

Corresponding Author:

Dr. Sajini Varghese,

Assistant Professor,

Department of Paediatrics,

ICH, Government Medical College,

Kottayam.

E-mail: drsajinidileep@yahoo.co.in

DOI: $10.14260 /$ jemds $/ 2017 / 1247$

(c) (i) $($ ) concentration is the most reliable indicator of anaemia at the population level. ${ }^{1}$ The most common cause for anaemia is nutritional, which occurs when there is a deficiency of a specific nutrient needed for $\mathrm{Hb}$ synthesis. ${ }^{3}$ Globally, iron deficiency is the most common cause for anaemia. Hence, iron deficiency anaemia (IDA) and anaemia are often used synonymously, and the prevalence of anaemia is used as a proxy for IDA. ${ }^{1}$ Children are more prone to develop iron deficiency because of high iron requirements due to their rapid body growth and low intake of iron from complementary foods.4, 5, 6 Anaemia is an indicator of both poor nutrition and poor health.

Anaemia has far reaching consequences if not detected and treated early including poor psychomotor development, lowered cognition, poor school performance and increased susceptibility to infections.3,7,8 In infants, iron deficiency anaemia adversely affects the immune status and increases the overall infant mortality. It also reduces the physical capacity and work performance of all age groups. 4

Iron deficiency anaemia can be effectively prevented and in case already developed, can be easily treated by simple measures. Hence, there is a dire necessity for comprehensive studies to determine the prevalence of anaemia in children in different regions and different socioeconomic groups to plan for effective intervention which in turn helps in better management. There are many population based studies on anaemia available. However, detection of anaemia is usually done when a child is attending the hospital for some other 
illness and hence a hospital-based study could provide a different perspective on the prevalence of anaemia.

\section{Objectives}

1. To study the prevalence and severity of anaemia among hospitalised children aged 6 months to 59 months.

2. To evaluate its association with gender, nutritional status, various systemic illness and duration of hospitalisation.

\section{MATERIALS AND METHODS}

This is a retrospective descriptive study conducted at Institute of Child Health, Government Medical College Kottayam. The case records of paediatric inpatients aged 6-59 months, maintained at the hospital medical records department were used to collect the study variables. The study was approved by the institute research and ethical committee.

The sample size was calculated to be 675 based on the prevalence of anaemia among paediatric inpatients from the previous study as $63.3 \%$ with $4 \%$ absolute precision. ${ }^{9}$ On an average, 600 patients are admitted per month. In order to collect complete required data fulfilling the sample size, it was decided to collect data from all patients aged six months to 59 months admitted on every 5 days interval during 2016. Records of children who were not tested for haemoglobin, who were readmitted, with pre-existing chronic illness, or with incomplete data were excluded. Children diagnosed to have other causes of anaemia other than nutritional as final diagnosis was also excluded.

Data pertaining to gender, age, weight, serum haemoglobin level, diagnosis that led to admission and duration of hospitalisation were collected. Patients were categorised by age as follows: 6 - 12 months, 13 - 24 months, $25-36$ months and > 36 months. Patients with multiple CBC, only the first test was taken into account. The WHO criteria (haemoglobin $<11 \mathrm{~g} / \mathrm{dL}$ ) was used to diagnose anaemia ${ }^{10}$ to categorise the degree of anaemia, the following cut-off points were used: $10.0-11 \mathrm{~g} / \mathrm{dL}$ - mild anaemia; 7.0-10 g/dL moderate anaemia; $<7 \mathrm{~g} / \mathrm{dL}$ - severe anaemia. A weight-forage indicator was used to evaluate nutritional status. To analyse this variable, the $\mathrm{z}$-score was used, with classification based on WHO standards: very underweight for age (z-score $<-3$ ); underweight for age (z-score $\geq-3$ and $<-2$ ); adequate weight (z-score $\geq-2$ and $<+2$ ) and overweight for age (zscore $\geq+2$ ). ${ }^{11}$ The $z$-scores of weight for age were calculated using the WHO growth chart.11

Data were entered in Microsoft Excel Sheet and analysed using SPSS version 24. Description of study parameters were given in frequency and percentages. Chi-square test was used to find the association between grades of anaemia and various study parameters. $P$ value less than 0.05 were considered as statistically significant.

\section{RESULTS}

675 consecutive case records of children aged 6-59 months were analysed to assess the prevalence of anaemia, whose characteristics are described in Table 1 . The group consisted of $56.9 \%$ boys and $43.1 \%$ girls. The predominant age group was $>36-59$ months $(31.9 \%)$ followed by $>12-24$ months. The majority of children had adequate weight (68.9\%). 19.56\% were under weight for age and $10.96 \%$ were very underweight for age. Only $0.86 \%$ were overweight for age.
Majority of the children were hospitalised for a period of 3-6 days (59.1\%). 171 children (25.3\%) were discharged after two days of admission. Most common cause for hospitalisation was illness of respiratory system (44.9\%) followed by central nervous system $(19.6 \%)$. Out of the 675 children, 379 (56.1\%) had anaemia ( $\mathrm{Hb}<11 \mathrm{~g} / \mathrm{dL})$ while 296 $(43.9 \%)$ had normal haemoglobin concentration $(\mathrm{Hb}>11$ $\mathrm{g} / \mathrm{dL})$.

\begin{tabular}{|c|c|c|}
\hline Characteristics & Frequency & Percentage \\
\hline \multicolumn{3}{|c|}{ Gender } \\
\hline Male & 384 & $56.9 \%$ \\
\hline Female & 291 & $43.1 \%$ \\
\hline \multicolumn{3}{|c|}{ Age distribution } \\
\hline 6 to 12 months & 157 & $23.3 \%$ \\
\hline 13 to 24 months & 185 & $27.4 \%$ \\
\hline 25 to 36 months & 118 & $17.5 \%$ \\
\hline$>36$ months & 215 & $31.9 \%$ \\
\hline \multicolumn{3}{|c|}{$\begin{array}{r}\text { Nutritional Status } \\
\end{array}$} \\
\hline Very Underweight & 74 & $10.96 \%$ \\
\hline Under Weight for Age & 132 & $19.56 \%$ \\
\hline Adequate weight & 463 & $68.59 \%$ \\
\hline Over weight & 6 & $0.89 \%$ \\
\hline \multicolumn{3}{|c|}{ System of Illness } \\
\hline Respiratory system & 303 & $44.9 \%$ \\
\hline Gastrointestinal & 51 & $7.6 \%$ \\
\hline Central nervous system & 132 & $19.6 \%$ \\
\hline Infectious diseases & 57 & $8.4 \%$ \\
\hline Renal & 47 & $7.0 \%$ \\
\hline Cardiovascular system & 10 & $1.5 \%$ \\
\hline Others & 75 & $11.1 \%$ \\
\hline \multicolumn{3}{|c|}{ Duration of hospitalisation } \\
\hline up to 2 days & 171 & $25.3 \%$ \\
\hline 3 to 6 days & 399 & $59.1 \%$ \\
\hline above 6 days & 105 & $15.6 \%$ \\
\hline \multicolumn{3}{|c|}{$\begin{array}{c}\text { Table 1. Description of Study Subjects based on their } \\
\text { Gender, Age, Nutritional Status, System of Illness and } \\
\text { Duration of Hospitalisation }(N=675)\end{array}$} \\
\hline
\end{tabular}

\section{Prevalence of Anaemia and Associated Factors}

Prevalence of anaemia was $56.1 \%$ in the study group (Figure 1) with $28.7 \%, 25.3 \%$ and $2.1 \%$ as mild, moderate and severe anaemia respectively (Figure 2). Among the anaemic children, $51 \%$ had mild anaemia, $45 \%$ had moderate anaemia and $4 \%$ were severely anaemic. The results of the chi-square test indicated that the proportion of anaemic cases decreased with age, varying from $71.3 \%$ in children between 6 and 12 months to $31.5 \%$ in children $>36$ months (Table 2). $68.6 \%$ of children in $13-24$ months and $44.9 \%$ in $25-36$ months were anaemic (Figure 3). Prevalence of severe and mild anaemia were more among 6-12 months whereas 13-24 months groups were more affected with moderate anaemia. These results were statistically significant ( $p$-value $=0.000$ ). Among 384 male children, 211 (54.9\%) were anaemic and among 291 female children, 168 (57.7\%) were anaemic. There was no statistical difference in the percentage of various grades of anaemia between male and female children $(\mathrm{p}=0.571)$ (Table 2). 
Anaemia was significantly correlated with nutritional status (weight for age). In our study, anaemia was more prevalent among malnourished children than well-nourished children ( $\mathrm{p}$-value $=0.049$ ). $68.92 \%$ of very underweight for age children were anaemic. Among underweight for age children, $59.85 \%$ had anaemia (Table 2). 36.6\% anaemic children had adequate weight. In our study, no statistically significant association was found between anaemia and system of illness ( $\mathrm{P}$ value $>0.05$ ) although we got a high prevalence of anaemia among children with central nervous system illness 59.9\% and respiratory illness 58.1\% (Table 2). Majority of children were hospitalised for a period of 3-6 days. But study could not find any significant relation between anaemia and duration of hospitalisation. ( $p>0.05)$.

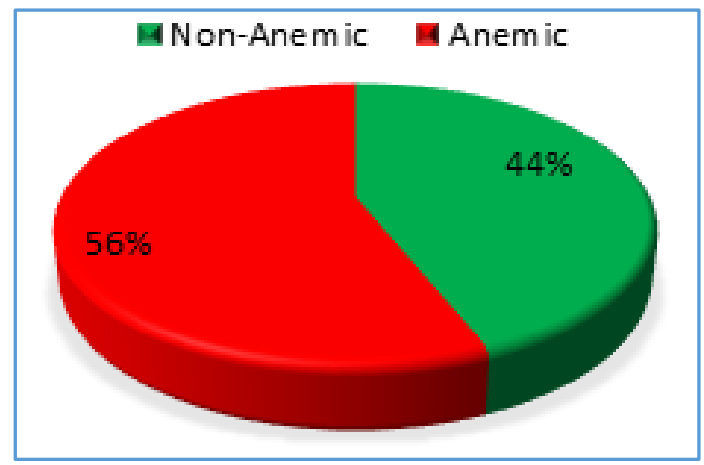

Figure 1. Anaemia Prevalence among Hospitalised Children

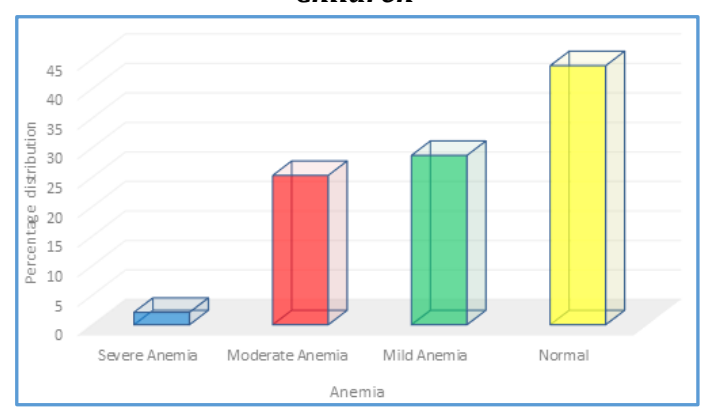

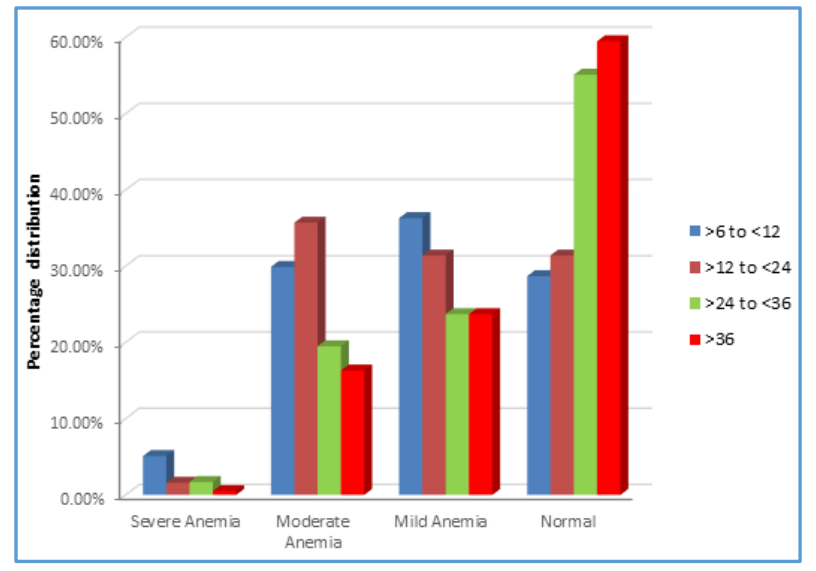

Figure 3. Distribution of Anaemia based on Age in Months

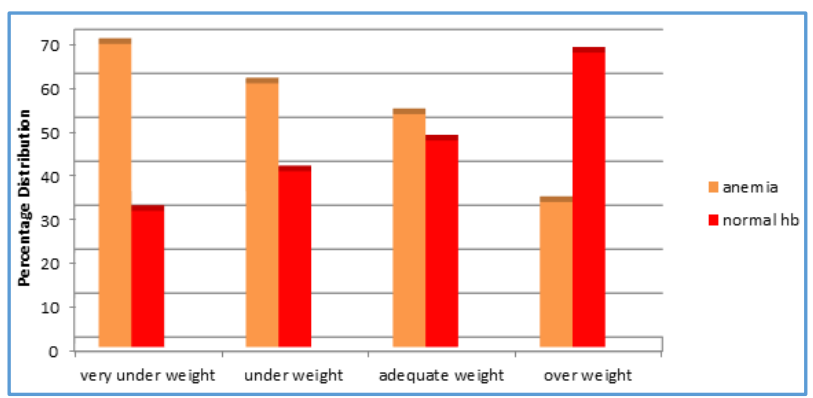

Figure 4. Anaemia and Nutritional Status

Figure 2. Grading of Anaemia

\begin{tabular}{|c|c|c|c|c|c|c|}
\hline \multirow{2}{*}{ Characteristics } & \multicolumn{4}{|c|}{ Grading of Anaemia } & \multirow{2}{*}{$\begin{array}{c}\text { Chi square } \\
\text { Value df }\end{array}$} & \multirow{2}{*}{$P$ value } \\
\hline & Severe & Moderate & Mild & Normal & & \\
\hline & & & Age in Months & & \multirow{5}{*}{$\begin{array}{c}\chi^{2}=64.11 \\
P=0.000 \\
d f=9\end{array}$} & \multirow{5}{*}{$\mathrm{p}<0.05$} \\
\hline $6-12$ & $8(5.1 \%)$ & $47(29.9 \%)$ & $57(36.3 \%)$ & $45(28.7 \%)$ & & \\
\hline $13-24$ & $3(1.6 \%)$ & $66(35.7 \%)$ & $58(31.4 \%)$ & $58(31.4 \%)$ & & \\
\hline $25-36$ & $2(1.7 \%)$ & $23(19.5 \%)$ & $28(23.6 \%)$ & $65(55.1 \%)$ & & \\
\hline$>36$ & $1(0.5 \%)$ & $35(16.3 \%)$ & $51(23.7 \%)$ & $128(59.5 \%)$ & & \\
\hline \multicolumn{5}{|c|}{ Gender } & \multirow{3}{*}{$\begin{array}{c}\chi^{2}=2.17 \\
p=0.571 \\
d f=3\end{array}$} & \multirow{3}{*}{$p>0.05$} \\
\hline Male & $10(2.6 \%)$ & $93(24.2 \%)$ & $108(28.1 \%)$ & $173(45.1 \%)$ & & \\
\hline Female & $4(1.4 \%)$ & $78(26.8 \%)$ & $86(29.6 \%)$ & $123(42.3 \%)$ & & \\
\hline \multicolumn{5}{|c|}{ Nutritional Status } & \multirow{5}{*}{$\begin{array}{c}\chi^{2}=17.5 \\
p=0.049 \\
d f=9\end{array}$} & \multirow{5}{*}{$\mathrm{p}<0.05$} \\
\hline Very underweight & $4(5.41 \%)$ & $25(33.78 \%)$ & $22(29.73 \%)$ & $23(31.08 \%)$ & & \\
\hline Underweight & $3(2.27 \%)$ & $27(20.45 \%)$ & $49(37.12 \%)$ & $53(40.15 \%)$ & & \\
\hline Adequate & $7(1.51 \%)$ & $118(25.49 \%)$ & $122(26.35 \%)$ & $216(46.65 \%)$ & & \\
\hline Overweight & $0(0 \%)$ & $1(16.67 \%)$ & $1(16.67 \%)$ & $4(66.67 \%)$ & & \\
\hline \multicolumn{5}{|c|}{ System of Illness } & \multirow{7}{*}{$\begin{array}{c}\chi^{2}=15.56 \\
p=0.623 \\
d f=21\end{array}$} & \multirow{7}{*}{$\mathrm{p}>0.05$} \\
\hline Respiratory & $7(2.3 \%)$ & $80(26.4 \%)$ & $89(29.4 \%)$ & $127(41.9 \%)$ & & \\
\hline Gastrointestinal & $2(3.9 \%)$ & $15(29.4 \%)$ & $12(23.5 \%)$ & $22(43.1 \%)$ & & \\
\hline Central nervous & $1(0.8 \%)$ & $40(30.3 \%)$ & $37(28.0 \%)$ & $54(40.9 \%)$ & & \\
\hline Infections & $1(1.8 \%)$ & $13(22.8 \%)$ & $20(35.1 \%)$ & $23(40.4 \%)$ & & \\
\hline Renal & $2(4.3 \%)$ & $9(19.1 \%)$ & $10(21.3 \%)$ & $26(55.3 \%)$ & & \\
\hline Cardiovascular & $0(0 \%)$ & $2(20 \%)$ & $2(20 \%)$ & $6(60 \%)$ & & \\
\hline
\end{tabular}




\begin{tabular}{|c|c|c|c|c|c|c|}
\hline others & $1(1.3 \%)$ & $12(16 \%)$ & $24(32 \%)$ & $38(50.7 \%)$ & & \multirow{5}{*}{$\mathrm{p}>0.05$} \\
\hline \multicolumn{5}{|c|}{ Duration of Hospitalisation } & \multirow{4}{*}{$\begin{array}{c}\chi^{2}=9.49 \\
p=0.148 \\
d f=9\end{array}$} & \\
\hline Up to 2 days & $1(0.6 \%)$ & $35(20.5 \%)$ & $51(29.8 \%)$ & $84(49.1 \%)$ & & \\
\hline 3-6 days & $9(2.3 \%)$ & $105(26.3 \%)$ & $119(29.8 \%)$ & $166(41.6 \%)$ & & \\
\hline$>6$ days & $4(3.8 \%)$ & $31(29.5 \%)$ & $24(22.9 \%)$ & $46(43.8 \%)$ & & \\
\hline
\end{tabular}

\section{DISCUSSION}

Most studies on anaemia are population based. Only few studies are conducted among hospitalised children, which limit comparative analysis of results. Our study identified a high prevalence of anaemia (56.1\%) among hospitalised children. A similar result has been reported in other Indian studies too. Muthusamy et al found that $63.3 \%$ children in the age group of less than 5 years were anaemic. ${ }^{9}$ Saba $\mathrm{F}$ et al had conducted a study in children between 6 months to 12 years at Bangalore also found that children between 6 months to 1 year were the most affected group with anaemia ${ }^{12}$ which was almost similar to our results $(71.3 \%)$. The prevalence of anaemia in preschool children (0-4 yrs.) of WHO countries of Africa, southeast Asia and eastern Mediterranean were $67.6 \%, 65.5 \%$ and $46.7 \%$ cases respectively. ${ }^{1}$ The prevalence of anaemia is much more lower in developed countries such as in America $29.3 \%$ and Europe $21.7 \% .^{1}$ In a study of children aged 12-23 months in two rural districts in India, $72 \%$ of children with anaemia had low ferritin levels. ${ }^{13}$ Another study done by Reha et al in Tanzania the overall prevalence rate of anaemia in the under 5 age group was $77.2 \% .^{14}$ The reasons for high prevalence of anaemia in children are increased iron requirements due to rapid growth, early weaning, low availability of foods rich in iron and dietary monotony. 15

The proportion of mild, moderate and severe anaemia in our study was $28.7 \%, 25.3 \%$ and $2.1 \%$ respectively. We found mild-to-moderate anaemia was noted in majority of cases which is in accordance with the study done by Saba F et a.$^{12}$ In our study, the prevalence of severe anaemia was significantly low. The relationship between anaemia and gender shows conflicting results. In our study, both male and female children are affected by anaemia but we could not find any statistically significant association between them ( $p$ value $=0.403$ ). In other studies also, there was no statistically significant difference in terms of gender with anaemia affecting boys and girls equally. ${ }^{11,15}$

Another important observation we found was anaemia was predominantly seen in malnourished children. $69 \%$ of very underweight and $60 \%$ of underweight children was found to be anaemic. In an Indian study, it was noted that there is an association between anaemia and malnutrition with lower mean haemoglobin levels in underweight and stunted children. ${ }^{16}$ Osório et al also found a higher prevalence of anaemia in malnourished children aged between 6 and 59 months in Pernambuco. ${ }^{17}$ Siegal EH et al have noted that stunting (30.8\%) and wasting (18.1\%) were prevalent in anaemic children studied between 4-17 months. ${ }^{18}$

Anaemia increases the risk of infection and many times is indirectly a reason for hospitalisation. Though we found a high prevalence of anaemia in children suffering from respiratory tract diseases and central nervous system diseases, statistical significant association could not be made. Lima et al reported a higher prevalence of anaemia in infants with infectious diarrhoea. ${ }^{19}$ Ramkrishna $\mathrm{K}$ et al studied haemoglobin level as a risk Factor for Lower Respiratory Tract Infections and identified anaemic children were 5.75 times more prone to lower respiratory infections compared to the control group. ${ }^{20}$ Prevention of anaemia due to whatever aetiology will reduce the incidence of LRTI.19

Most studies could not find any relation between the prevalence of anaemia and length of hospitalisation. The length of hospital stay may be related to other factors such as the severity of the disease, presence of other complications and care. ${ }^{15}$ In our study, although the length of the hospital stay was not significantly associated with anaemia, it is possible that anaemia can aggravate the primary disease, thereby prolonging duration of hospital stay.

Iron Deficiency Anaemia is the end stage of iron deficiency and reflects only the tip of the "iceberg" problem. ${ }^{21}$ To prevent the development of anaemia, Indian Government recommends iron supplementations to younger children. ${ }^{22}$ Steps must be taken by local authority for educating the mothers about the benefits of exclusive breast-feeding in the first six months of life followed by appropriate complementary feeding practices. But still we have a long way to eliminate iron deficiency in children.23, 24 Our results of high prevalence of anaemia are in agreement with other studies in India and indicate the need for a strict iron supplementation programme in order to help a larger number of at-risk children.

\section{CONCLUSION}

A large proportion of hospitalised children less than 5 years of age were found anaemic. Prevalence of anaemia was more among infants and malnourished children. So, nutritional anaemia especially iron deficiency anaemia should be considered as a public health problem in these age groups. Iron supplementation programmes should be integrated into broader public health programmes which are directed to the target groups. Therapeutic supplementation should be part of the health care delivery system.

\section{REFERENCES}

[1] De Benoist B, McLean E, Egli I. eds. Geneva: WHO Press, World Health Organization, 2008. WHO/CDC. Library Cataloguing-in-Publication Data. Worldwide prevalence of anaemia 1993-2005. WHO global database on anaemia: p. 40 . whqlibdoc. who.int/publications/2008/9789241596657_eng.pdf

[2] Arnold F, Parasuraman S, Arokiasamy P, et al. Nutrition in India, in National Family Health Survey (NFHS-3) India 2005-06, 2009. http://www.rchiips.org/nfhs/nutrition report for website 18sep09.pdf.

[3] Baker RD, Greer FR, Committee on Nutrition American Academy of Pediatrics. Diagnosis and prevention of iron deficiency and iron-deficiency anaemia in infants 
and young children ( $0-3$ years of age). Paediatrics 2010;126(5):1040-50.

[4] World Health Organization. Iron deficiency anaemia assessment, prevention and control. A guide for programme managers. Geneva, WHO, 2001.

[5] UNICEF/United Nations University/World Health Organization. Iron deficiency anaemia. assessment, prevention, and control: a guide for programme managers. Document WHO/NHD/01.3. Geneva: World Health Organization, 2001. f $^{-1}$

[6] UNICEF: Spotlights: Iron, the State of the World's Children. United Nations Children Fund: focus on nutrition. 1998: p. 78.

[7] Brown CV, Brown GW, Bonehill B. Iron deficiency and its functional consequences. Alaska Medicine 1967;9:93.

[8] Walter T, de Andraca I, Chadud P, et al. Iron deficiency anaemia: adverse effects on infant psychomotor development. Paediatrics 1989;84(1):7-17.

[9] Muthusamy BG. Venugopal V, Sumithra S. Prevalence of anaemia among the hospitalized children in a rural tertiary care teaching hospital. Int J Contemp Pediatr 2017;4(2):431-7.

[10] Preventing and controlling anaemia through primary health care: a guide for health administrators and programme managers. Geneva, World Health Organization, 1989. http://www.who.int/nutrition /publications/micronutrients/anaemia_iron_deficienc y /9241542497.pdf

[11] World Health Organization. WHO child growth standards: length/height-for-age, weight-for-length, weight-for-height: and body mass index-for-age. Methods and development. WHO (nonserial publication). Geneva, Switzerland: WHO, 2006.

[12] Saba F, Poornima S, Balaji PA, et al. Anaemia among hospitalized children at a multispecialty hospital, Bangalore (Karnataka), India. J Family Med Prim Care 2014;3(1):48-53.

[13] Pasricha SR, Black J, Muthayya S. Determinants of anaemia among young children in rural India. Paediatrics 2010;126(1):e140-e9.
[14] Simbauranga RH, Kamugisha E, Hokororo A, et al. Prevalence and factors associated with severe anaemia amongst under-five children hospitalized at Bugando Medical Centre, Mwanza, Tanzania. BMC Hematol 2015;15:13.

[15] Dos Santos RF, Gonzalez ESC, de Albuquerque EC, et al. Prevalence of anaemia in under five-year-old children in a children's hospital in Recife, Brazil. Rev Bras Hematol Hemoter 2011;33(2):100-4.

[16] Awasthi S, Das R, Verma T, et al. Anaemia and undernutrition among preschool children in Uttar Pradesh, Indian Pediatrics 2003;40(10):985-90.

[17] Osório MM, Lira PI, Batista-Filho M, et al. Prevalence of anaemia in children 6-59 months old in the state of Pernambuco, Brazil. Rev Panam Salud Publica 2001;10(2):101-7.

[18] Siegel EH, Stoltzfus RJ, Khatry SK, et al. Epidemiology of anaemia among 4-17 month-old children living in south central Nepal. Eur J Clin Nutr 2006;60(2):22835.

[19] Lima AC, Lima MC, Guerra MQ, et al. Impact of weekly treatment with ferrous sulfate on haemoglobin level, morbidity and nutritional status of anaemic infants. J Pediatr (Rio J) 2006;82(6)):452-7.

[20] Ramakrishnan K, Harish PS. Haemoglobin level as a risk factor for lower respiratory tract infections. Indian J Pediatry 2006;73(10):881-3. medind.nic.in/icb/t06/i10/icbt06i10p881.pdf.

[21] Filer IJ. Iron nutritional status defined. In dietary iron: from birth to two years. New York, USA: Raven Press 1989:19-36.

[22] Kotecha PV. Nutritional anemia in young children with focus on Asia and India. Indian Journal of Community Medicine 2011;36(1):8-16.

[23] Indian Paediatrics http://www.indianpediatrics.net/apr2003/apr-293295.htm.

[24] Prevalence of anaemia among children (\% of children under 5) http://data. worldbank.org/ indicator/SH.ANM.CHLD.ZS. 